\title{
EVAluATING A CULTURAL POLICY IN THE DANCE SECTOR. DOES EFFICIENCY ALWAYS MEAN ACHIEVING GOALS?
}

\author{
María José Del Barrio-Tellado \\ Department of Accounting and Business \\ Faculty of Commerce. University of Valladolid \\ E-mail: mjose@emp.uva.es \\ Luis César Herrero-Prieto \\ Department of Applied Economics \\ Faculty of Commerce. University of Valladolid \\ E-mail: herrero@emp.uva.es
}

\begin{abstract}
This work aims to evaluate cultural policies, specifically in the dance sector, an area which has received scant attention in economic literature so far. Data Envelopment Analysis (DEA) is applied to evaluate public programme performance and the stakeholders involved therein. We select a Spanish public policy supporting dance as a case study, which includes public authorities, theatres and dance companies. The former provide the funding while the others offer the artistic idea taken to the audience. We find that efficiency in resource performance often runs counter to other cultural aims such as increasing audiences or extending repertoire diversity.
\end{abstract}

KEYWORDS: cultural policy evaluation, efficiency evaluation, dance sector, data envelopment analysis, Spain

JEL CODES: H44; Z11; C61; Z18 


\section{Introduction}

Economic studies exploring dance have failed to receive as much attention as other cultural goods and services. Framed within the performing arts, dance reflects many features inherent to the sector, such as the labour intensive nature of its productions and a cost structure that evidences few significant gains in productivity, thereby condemning it to the typical performance outcomes resulting from the so-called costs disease (Baumol and Bowen, 1966) and inevitably having to rely on public funding. This is why it is interesting to evaluate public intervention in this area, particularly in a programme aimed at promoting the dance sector, where public funds are committed to achieving certain objectives. The dance spectrum covers a very broad area. One part of dance shows involves the most refined cultural and classical version, ballet, and therefore resembles studies in opera, with which they often share an orchestra and resident theatre. Public intervention in this field, in the form of maintaining so-called national dance companies is justified on the basis of merit goods arguments, and even protection of inherited cultural heritage (Schimmelpfennig, 2003). This may be extended not only to classical ballet, but also to other ethnic dances that are the fruit of cultural idiosyncrasies, such as tango and salsa in Colombia or flamenco in Spain (Aoyam, 2009). Yet these types of dance live alongside other more popular forms of dance that have survived in the market as viable projects. These range from musicals, which combine dance, acting and singing and that prove very popular, to a wide variety 
of differing dance styles (ethnic, popular, hip-hop, urban dance, etc.) in which many professionals and aficionados survive, offering artistic productions and often focusing on teaching dance as a leisure activity.

As pointed out, the economic literature on dance remains limited. For instance, attendance and the drivers of cultural participation in the sector have been analysed by Boroviecki and Marvao (2017) and Heredia-Carroza et al. (2020). Skinner (2013) argues that dancing contributes to higher levels of happiness, social inclusion and better ageing, even for those who do not practice dance professionally. As regards the impact on social capital, some studies (Lee, 2013; Gómez-Zapata et al. 2020) reveal that public programmes of artistic training or practice have significant effects on participants and organizations because they are involved in a common process of creativity that favours pride and social cohesion. Artistic activity also contributes to economic growth not only due to the size of the sector itself (Cohen et al. 2003) but also because creativity generates returns in terms of attracting visitors, inhabitants and investments (the so-called artistic dividend, Markusen and Schrock 2006). For instance, in the dance sector, positive externalities have been evidenced by Palma et al. (2013) for the spring fiestas in Seville, Spain.

Following the survey, as regards labour market studies in the dance sector Jeffri (2005) examines the challenges and realities of a dancer's career transition in several countries, whilst Montgomery and Robinson (2003) analyse the earnings and working conditions of dancers, showing that returns to dance are 
small and that many dancers have a second job to increase their incomes. Segers et al. (2010) and Heredia-Carroza et al. (2019) also find artist vulnerability in this sector as well as problems concerning their work vis-à-vis being valued as talented performers. Finally, Labaronne (2019) explores the organizational practices of large European dance companies and Smith (2003) shows how public grants attract private fundraising in non-profit dance companies in the USA. Studies evaluating efficiency in the dance sector are relatively scarce (Del Barrio-Tellado et al. 2020) although there are several works aimed at evaluating theatres, as the main venues where performing arts are carried out.

The present study thus addresses one of the lesser explored issues in this domain; namely, the evaluation of a cultural policy designed to support the dance sector where various stakeholders are involved and whose performance could therefore be assessed: dance companies as cultural creators, the venues where they stage their productions and the policy-makers who give funds and define the aims to be fulfilled in the cultural project. For this, we use participation in an incentive programme for dance fostered by the public sector in Spain between 2010 and 2016, specifically the Danza a Escena programme, promoted by the Spanish Ministry of Culture through the National Institute of Performing Arts and Music (INAEM). The methodological innovation lies in the fact that the activity evaluated is carried out jointly within a cultural programme by two kinds of bodies (dance companies and performance venues), forcing us to identify the goals established for each in the public project and to 
assess the achievements accomplished by each separately. The aim is not, therefore, to evaluate stakeholder behaviour in the market but to gauge their performance in a specific cultural programme in the field of dance promoted by the public sector, and consequently also to assess how policy-maker aims are fulfilled. We use DEA to solve an optimization problem for both entities: how to maximize certain goals set out by the public programme, taking into account their own resources and the funds received. The outcomes to emerge will therefore prove useful in three aspects: estimating success of dance companies in performing arts production, measuring management performance when handling performing arts venues and, finally, assessing the effectiveness of a public incentive programme. This application might be considered as a case study reference. We finally seek to ascertain whether there is a trade-off between efficiency and artistic objectives; in other words, whether companies and theatres sacrifice resources when producing and programming dance shows for the purpose of quality, artistic diversity and audience success which are the public project's main aims.

The work is organised into four sections. After this introduction, section 2 provides a review of works addressing efficiency and productivity in performing arts. Section 3 contains the empirical application, first describing the institutional design of the public dance support programme and its main features. This is followed by the methodological approach applied based on DEA and an explanation of the analytical strategy of efficiency evaluation for 
each stakeholder. We then present the research results. The work finishes in section 4 with the main conclusions reached.

\section{Literature review on the efficiency evaluation of performing arts sector}

Works related to the efficiency evaluation of cultural institutions have made great strides in recent years (Fernández-Blanco et al., 2013). This interest stems from the need to measure the management performance of the public institutions that provide cultural goods and services using rational criteria. This is crucial at the present time when ensuring survival depends on an agreement between artistic values, social function and rational management criteria, given the dwindling financial resources available. This rekindles interest in evaluating how efficiently cultural entities are managed in an effort to gauge the efficient

use of available resources. In this regard, efficiency studies -into any branch of activity- seek to link the resources employed to the aims achieved. Measuring the relation or gap between the two may be addressed in a number of ways. Most works use frontier techniques which examine each institution's position vis-à-vis a frontier of efficient behaviours that can be estimated through parametric or non-parametric methods. Parametric models for estimating stochastic frontiers have often been used in the field of culture and more specifically in the performing arts sector. Framed within this category is the work of Zieba (2011), which estimates the production technology and production efficiency of a significant sample of Austrian and Swiss theatres, 
and Castiglione et al. (2018) who evaluate the determinants of a firm's technical efficiency in the Italian performing arts sector by estimating a stochastic production frontier for an unbalanced panel of 107 firms.

Another group of studies addressing efficiency in the performing arts sector draws on non-parametric techniques, principally (DEA), to estimate the frontier of institutions' efficient behaviour. This approach has been less common in the field, although it does adapt conveniently to the features of the sector where production processes are highly complex and involve different types of activities and intermediaries. These techniques are therefore suited to evaluating multi-output production functions. From this standpoint, DEA efficiency evaluation techniques are the preferred option in works such as Marco-Serrano (2006), who evaluate the technical efficiency of a regional network of theatres in Spain using different performing models, or Wu et al (2020) who evaluate the efficiency of the commercial performing arts sector in China. In the area of symphony orchestras, Hong (2014) posits a two-stage DEA model that evaluates the efficiency of fundraising activities for a set of 48 young orchestras in the United States. Finally, in the specific case of the dance market, Del Barrio-Tellado et al. (2020) evaluate the performance of American dance companies using Network-DEA and then dividing the production process into three stages, fundraising, artistic production, and social impact. Their results show how dance companies focus their efforts mainly on artistic and creative purposes, regardless of what effects these criteria might have on audience 
success. This focus on "art for art's sake" explains why most dance companies are non-profit entities, and depend on fundraising. Additionally, donors seem to appreciate the whole entity's performance rather than results concerning public success and social impact.

\section{Empirical study}

3.1 Case study: a cultural policy for supporting the dance sector in Spain

Our case study involves evaluating a dance circuit called Danza a Escena, promoted by the Spanish Ministry of Culture, which seeks to provide a meeting point to bring together dance companies and publicly owned theatres. The general aim of the public programme is to increase the presence and visibility of dance productions and spectacles in the programmes of publicly owned performance venues. Its specific goals are: to increase the number of dance shows, foster the diversity and languages of artistic formats, as well as promote spectator numbers and the creation of new audiences. The project involves both the performance venues that make up and choose the final cultural supply that reaches the public and the companies who put forward their artistic proposals to a panel of experts for initial selection, and which is then revalidated through the selection of the actual performance venues. We obviously add the State (Ministry of Culture), who fund both the artistic creation (dance companies) as well as its staging at venues (theatres' repertoire): the programme guarantees 
$50 \%$ of the chosen company's fees for each performance with the venues agreeing to pay the remaining fifty percent, which in turn comes from funds requested from the public programme for its repertoire ${ }^{\mathrm{i}}$. There are no provisions vis-à-vis regulating ticket prices for the shows, and venues are given a free hand in this matter, although they are publicly owned theatres and prices are always low.

Organising the activity in this way enables the objectives to be shared amongst the various stakeholders. Venues have the capacity to include dance shows in their programming, and the selection criteria allow them to focus their activity on fostering diversity, all of which is geared towards boosting audience attendances as well as attracting fresh audiences to the world of dance. In addition, dance company activities may be linked to the goal of increasing spectator numbers and creating new audiences, since they are related to the success of their productions by presenting high-quality and appealing shows ${ }^{\mathrm{ii}}$. How well these two agents perform in the programme will be measured in terms of what contribution each makes towards achieving the specific objectives assigned to them in the public project. This approach leads us to assess the performance of the three pillars involved in the cultural policy: both the cultural agents participating in it as well as how successful policy-makers have been in achieving their goals.

The source of information for the work is provided by annual reports of the above-mentioned dance circuit between 2011 and 2016. As can be seen in Table 
1, during the six-year period analysed, the programme has spawned the production of 122 new dance shows, which has led to 746 performances, 88 staged by the theatres themselves and the rest $(658$, or $88 \%)$ funded by the programme. Each new work has been performed an average of six times, although this figure has varied substantially. The number of dance companies involved in the programme is 91 , with 161 theatres and venues, and with a total of 126,642 spectators. Average attendance per performance was 192 people and each venue attracts an average of 787 spectators, close to the mean capacity for the theatres although, again, figures vary enormously. The total amount devoted to directly funding dance shows by the INAEM over the six years studied is over one and a half million euros. This accounts for half of the resources provided to the programme, with the total amount of public funding made available to the programme exceeding three million euros if we add the cofunding provided by performance venues. As an indication, mean expenditure of the whole programme per spectator was $12 €$ and per show was $2,352 €$. Mean funding per new artistic production is $12,688 €$ and $9,614 €$ per theatre. In order to prevent outliers entering the analysis which might reflect situations of closure or irregular participation, open public spaces are excluded as are venues that only took part in the programme once. Ninety-eight different venues were thus identified that provide significant and regular participation over the six years the programme was running. This represents $60 \%$ of the venues participating, although they cover $86 \%$ of the shows and $80 \%$ of the subsidies over the six years. Nevertheless, we took the total number of dance companies participating 
in the programme, a figure which came to 91 over the period analysed and obviously all of the dance productions, which came to 122 . This is the basic sample involved and whose performance in the dance circuit we aim to evaluate. In order to make the scope of this public programme more expressive and tangible, Figure 1 shows the territorial distribution of the main results and stakeholders. Artistic production (dance company works) is mainly concentrated in Madrid and Catalonia, together with Valencia and Andalusia in a second tier. However, the theatres involved are eminently located in inner regions, as are spectator numbers, thereby reflecting a centre-periphery model in the market for artistic production and distribution in the dance sector in Spain. The distribution of funds therefore follows this pattern of relative concentration.

\section{TABLE 1}

\section{FIGURE 1}

\subsection{Methodological approach and data}

As pointed out, in order to identify the most efficient behaviour in the programme, both in terms of venues and dance companies, we employed DEA, which allows us to consider multiple inputs and outputs when assessing performance, without having to define the explicit production function corresponding to the activity assessed. Use of DEA makes it possible to calculate the relative efficiency of a set of units, defined as the relation between the weighted sum of the inputs and the weighted sum of the outputs. Efficiency 
indices are calculated by solving a mathematical programming problem which, in its output oriented version, and considering a set of units to be evaluated (theatres or dance companies), $\mathrm{m}$ inputs and s outputs, may be expressed as follows (Charnes et al, 1978):

$$
\begin{gathered}
\min _{\mu, \delta} \omega_{0}=\delta^{t} x_{0} \\
\mu^{t} y_{0}=1 \\
\delta^{t} X-\mu^{t} Y \geq 0 \\
\mu^{t}, \delta^{t} \geq I \varepsilon
\end{gathered}
$$

with $\mathrm{X}$ and $\mathrm{Y}$ being the matrices of inputs and outputs of order $m \times n$ and $s \times n$ respectively; $x_{0}$ and $y_{0}$ the vectors of inputs and outputs of each unit analysed; and $\delta$ and $\mu$ are the vectors representing the weights of the inputs and the outputs, respectively.

In its envelopment form, the problem can be set out as follows:

$$
\begin{aligned}
& \max _{\varphi, \lambda, s^{+}, s^{-}} \quad z_{0}=\varphi+\varepsilon\left(I s^{+}+I s^{-}\right) \\
& \varphi y_{0}-\lambda Y+s^{+}=0 \\
& \lambda X+s^{-}=x_{0} \\
& \lambda, s^{+}, s^{-} \geq 0
\end{aligned}
$$


Solving this model provides an optimal solution $\left(\varphi^{*}, s^{+}, s^{-}\right)$, being $\varphi^{*} \geq 1$. Therefore, the greater the $\varphi^{*}$, the more inefficient the unit analysed. A unit is classified as technically efficient if $\varphi^{*}=1$ and all the slacks are null $\left(s^{+}=\right.$ $\left.0, s^{-}=0\right)$. In an output oriented model, the measure of technical efficiency can be expressed as $1 / \varphi^{*}$. In the form the model is set out, it provides technical efficiency (TE) assuming constant returns to scale, which is the most common hypothesis in efficiency evaluation studies (Charnes et al., 1978).

One limitation traditionally ascribed to DEA is its sensitivity to variations in the sample. Nevertheless, this limitation may be overcome by applying bootstrap procedures. To do this, based on the original sample, other pseudo-samples are obtained that increase the initial amount of data, thus enabling statistical inference. We therefore obtain an estimator of efficiency from the initial information, as well as the confidence intervals with a certain level of significance, allowing us to determine whether the value obtained for the estimator is representative or not. The Simar and Wilson algorithm (1998) allows us to apply the bootstrap procedure to obtain robust efficiency indices.

We opted to follow an output oriented model in which the aim is to maximise the proportional increase in outputs that could be achieved by the unit evaluated, given its input levels. We understand that output orientation is the most appropriate for the case in hand since we aim to maximize stakeholders' results, which identify with the main aims of the cultural policy (audience, supply, and diversity), taking into account available resources, public funds included and 
their own resources: theatre capacity and artistic production in dance companies, respectively. This can be seen more specifically in attached Figure 2, which we now explain.

\section{FIGURE 2}

First, we evaluate the participation of venues in the programme as channels of cultural supply, and whose performance involves maximising audience appeal and programme diversity, subject to their material and financial resources. A simple production function of the venues is thus established that identifies the funding provided by the programme as input variables; in other words, half of the appearance fees for the companies' shows (FUNDING-PV) and the available capacity (CAPACITY) ${ }^{\mathrm{iii}}$. The chosen output variables are the number of spectators (SPECTATORS-PV) as a measure of the programme's total impact, the number of scheduled works (WORKS-PV) as a measure of fostering dance shows in the venues' repertoire, and the number of scheduled genres (GENRES), seen as a measure of the venue's contribution to disseminating new styles and trends to attract new audiences ${ }^{\text {iv }}$. Second, we have the evaluation of the dance companies participating in the programme. Whilst the venues' function is more closely related to management and scheduling, dance companies make the artistic contribution in the sense of offering shows that are appealing to the public and also contribute towards diversity in the supply of dance, taking into account their own specialization. In this case, output is measured through the number of spectators (SPECTATORS-DC) drawn by 
each company, whereas resources are defined as the funding secured (appearance fees paid by the programme) (FUNDING-DC) and the number of works (WORKS-DC) the company offers in the programme. In both instances, companies and venues, a single time window is considered spanning the six seasons the programme for promoting dance was running. This is also appropriate to the purpose of this work, which is to evaluate cultural policy efficiency through the participation of the agents involved ${ }^{\mathrm{v}}$.

Table 2 presents the basic description for the input and output variables considered in each model together with the main descriptive statistics. Data reflect substantial differences in terms of participation in the programme by the various stakeholders. It can first be seen how no company has taken part in more than three editions of the programme, with the mean number of participations being 1.34. This is explained by the large number of projects companies presented in each edition, which makes it difficult for companies to access the programme $^{\mathrm{vi}}$, but also because the market for dance companies is very volatile with companies disappearing, changing or adapting to specific projects. As regards performance venue participation, substantial differences can also be seen in terms of the diversity of works and genres scheduled; most focus their offer on a limited range of genre (the median is three) with around five works programmed, whilst others seek to provide a diversified supply embracing a wide range of genres. As for the capacity variable, major differences can also be seen between programme participants, as well as for the attending audiences, 
where the average is 938 spectators per venue, although this can also be determined by the number of performances scheduled by theatres.

\section{TABLE 2}

\subsection{Results}

Table 3 shows the general results of the efficiency analysis of the various stakeholders involved in the public programme aimed at fostering dance in Spain. The first three columns show technical efficiency, pure technical efficiency and scale efficiency data. In order to correct biases in technical efficiency estimations, we applied a bootstrap procedure with 5,000 iterations so as to obtain the robust efficiency indices displayed in the final three columns, although the structure of the results does not differ, except when smoothing efficiency levels. Results seem to suggest that performance venues are more efficient than dance companies at meeting the programme's objectives, basically production and distribution of dance shows as well as the increase in spectator numbers. A detailed look, however, does reveal certain differences that merit highlighting.

We thus first evaluate venue performance, for which we built three different models. The first, called the multi-output model, links the resources used, evaluated in terms of venues' capacity and the funding received from the programme, with all of the goals pursued, measured through the variables for the number of spectators, number of works programmed and range of styles 
shown (see Figure 2). These evaluation results point to a $60.07 \%$ mean level of efficiency for performance venues over the period the programme was in operation, such that theatres might be expected to improve the established objectives vis-à-vis programming and attracting spectators by $40 \%$ using the same resources. There seems to be a gap between performances due to purely technical reasons $(84.49 \%)$ and scale reasons $(71.38 \%)$, highlighting problems of diversity and size and evidencing that smaller venues might hold an advantage in terms of efficiency for standard programmes with similar resources.

\section{TABLE 3}

Which are the most efficient venues? Table 4 shows the results of the multioutput evaluation model classified into ranges. Data confirm that those with the best efficiency results are the venues who participate least in the circuit; in other words, those scheduling a smaller number of works and styles and who draw a lower average number of spectators, which seems to run counter to the aims of the programme. As pointed out earlier, these are small venues that boast the lowest mean capacity (433.7 seats) and offer fewer tickets, which is linked to the number of scheduled performances. This group includes some theatres located in intermediate size towns and cities that have hardly any competition from other venues and which, by offering a well-measured programme of dance shows and with only limited resources, are able to draw audiences and achieve their goals at a lower relative cost. In contrast, less efficient theatres in terms of 
resource allocation are venues with a larger capacity and that offer more tickets, in other words more shows, because they provide a more diverse and intense dance programme. They also attract a larger mean number of spectators although, following the allocative logic of the model, they do so at a greater relative resource cost. Here we find an initial discrepancy between individual efficiency results and meeting the programme's aim of promoting dance, since venues that more closely meet the programme's objectives or that provide a wide and varied schedule and increase audience numbers are those which do so at the greatest relative cost of resources in terms of excess of funds and capacity. In sum, they are less technically efficient. This is the first evidence of the tradeoff between efficiency and accomplishing cultural goals.

\section{TABLE 4}

The fact that some venues which only programme shows covering one or two styles achieve the best positions in the evaluation might suggest that certain dance styles are more popular with audiences. However, the venues' mission is not only to draw audiences to the shows. Their ability to help disseminate new formats and genres is also valued in the public programme. In order to separate the results of these two objectives, which might lead to conflicting outcomes, we devised two new evaluation models: a demand oriented model, where the production function of the theatres takes only one output into consideration, measured in terms of spectators, and a supply oriented model where, with the same resources, output involves a richer programme, in other words, staging a 
greater number of works and offering a wider range of styles. The mean efficiency results for the two models are quite similar (42 and 47 efficiency rates, respectively, as can be seen in Table 3). Nevertheless, there are differences in the composition of the efficiency ranges as regards the scale of venues. In fact, as seen in Table 5, the most efficient venues in the demand model are medium size theatres that schedule a small number of shows and styles but which enjoy audience success. Specifically, these are specialised venues that focus on programming children's shows and on offering new styles (urban dance, hip-hop and circus dance), these being the styles that seem most popular amongst audiences. In contrast, when there is a greater diversity of works and styles, which obviously corresponds to larger theatres, mean efficiency in terms of attracting audiences drops. We therefore again find that the less efficient venues in terms of demand are those scheduling a more intense and diverse dance repertoire, which again supports the hypothesis set out in the title of the work.

\section{TABLE 5}

As regards the supply model, the results classified into efficiency ranges are shown in Table 6. The highest efficiency levels are seen to correspond to smaller venues and, again, are ones that specialise or that offer a short programme in terms of styles and a low mean number of spectators. Venues offering larger and more diverse repertoires correspond to larger theatres that make a greater effort in terms of cost due to their scheduling more shows and more varied 
shows. In sum, the results with these specifications in the production function again point to the same overall result, in that the most efficient theatres are the smaller ones that offer shorter and more specific repertoires. This is therefore an optimal result in technical terms of use of resources, yet is far removed from the criteria of diversity and spreading repertoires stated by the programme that seeks to promote dancing.

\section{TABLE 6}

Changing the stakeholder, and looking at the results obtained when evaluating dance company performance, Table 3 shows low mean efficiency levels $(35.86 \%)$ which, in this case, are more due to technical reasons $(42.21 \%)$ than to scale reasons $(86.88 \%)$. In this case, it should be remembered that dance companies produce, at most, one work for the programme each year and that, therefore, the resources available to measure their success and performance are the number of times they have taken part over various editions of the programme, with the mean contribution being 1.34 works over the period studied (Table 2).

Table 7 describes the dance companies in terms of efficiency levels, and shows how the most efficient companies are those that have most often taken part in the programme in terms of number of works produced, with a high number of shows and also reaching a high mean number of spectators, which reflects those productions' high degree of success. In this case, we do establish a direct relation between efficiency and fulfilling the programme's objectives. Firstly, 
these are companies that were awarded the required accreditation to take part in the programme on a regular basis. In addition, they are companies that take part with a greater number of shows because they have passed the experts' filter and subsequent selection by venues. Finally, they are also the most popular amongst the public, since they are able to attract the highest mean number of spectators.

\section{TABLE 7}

Continuing with this line of argument, we once again sought to find out the public's preferences for certain styles. Table 8 shows companies' mean efficiency indices for six groups of styles that sum up the various types of dance in the programme. As expected, the highest efficiency data correspond to companies working in the area of children and new styles (urban dance, circusdance, vertical dance, etc.). Yet these are not the companies who most often take part in the programme; the most numerous sector is contemporary dance with 32 companies and 46 new works and which, nevertheless, displays low levels of efficiency. Nonetheless, children and new styles with relatively fewer productions stage more performances (8.1 and 7.2 shows per work, respectively) Explaining this leads us to suppose there are, in practice, two thematic dance circuits. One specialises in children and new dance formats, and has a greater impact in terms of audience. It also tends to extend the tour to medium-size venues located in intermediate size cities where there is little cultural competition, such that performance outcomes are optimal in technical terms. In contrast, contemporary, neoclassical and Spanish dance companies 
mainly perform in larger theatres in major cities where there is greater cultural competition in the city and in the theatre's actual programming, such that results in terms of efficiency in the use of resources are poorer. This thematic duality ${ }^{\mathrm{vii}}$, which has implications for both the structure and size of companies, as well as how they are distributed around the venues, means that the efficiency results of the promotion programme through participant performance are not as consistent as might be expected.

\section{TABLE 8}

\section{Discussion and conclusions}

Although different contributions have been made to performance analysis in the performing arts sector, only rarely has the dance sector been taken as a specific case study. In this regard, our work seeks to make an original contribution to a sector, dance, where the survival of creators and performers who are outside the upper echelons of national companies and other resident companies is closely linked to public allocation of resources through promotion programmes. The analytical strategy we follow is to evaluate efficiency in a publicly-run support programme in the dance sector from a three-fold perspective linked to the performance of the various agents involved: dance companies, venues, and policy-makers.

Our work focuses on evaluating the performance of a specific cultural policy for promoting dance; the Danza a Escena circuit set up by the Spanish Ministry 
of Culture and whose particular aims are to increase the number of dance shows, broaden the range of artistic styles and boost the number of spectators as well as create new audiences. Our aim was not to assess the programme's progression over time but to gauge the contribution made by the principal stakeholders involved (venues and dance companies) towards accomplishing the programme's objectives (public purposes defined by the government). To achieve this, we design two kinds of production function linked to each cultural stakeholder's activity, which we relate to achieving the programme's objectives. Venues seek to maximise the number of spectators, as well as the size and range of their repertoires by using certain material (available capacity) and financial resources (programme subsidies). For their part, dance companies aim to achieve the greatest possible audience success in the programme, based on their artistic productions and the funding received. They are evaluated using non-parametric frontier techniques, specifically DEA.

In this regard, the results prove paradoxical, since the most efficient venues are those that are smaller and that offer a shorter and more monothematic programme in terms of dance shows, contradicting the aims of the promotion programme. In contrast, the evaluation of dance companies does evidence a direct relation between effectiveness and quality, measured in terms of artistic production and audience success. Although consistent with the rationale of optimal use of available resources, these results mask problems of scale diversity, both in companies and venues, particularly in the thematic diversity 
of artistic dance productions, which has different implications vis-à-vis distribution strategy and public interest. In this regard, there seems to be a kind of twin thematic circuit. On the one hand, dance shows geared towards children and new styles of dance are extremely popular among the general public and are widespread, particularly in medium size theatres and venues located in intermediate size cities that have little cultural competition, such that they display high levels of efficiency. In contrast, contemporary, neoclassical and Spanish dance shows tend to have greater technical requirements and prove more costly. Even though a major effort may be made when creating new artistic productions, these tend to be scheduled for larger theatres located in cities with bigger populations and that have greater competition in terms of cultural and leisure activities. Performance evaluation in terms of the resources used and the impact among the public is seen to be less favourable.

These results have major implications with regard to cultural management and policy-makers. Firstly, they evidence the appropriateness of evaluating programmes that support cultural promotion by gauging the performance of the various stakeholders involved, particularly in the dance sector, where only a few studies exist. Secondly, they reflect the need to assess the efficiency of cultural promotion programmes by measuring to what extent the aims for which they were designed have been met, not only through the efficient use of resources, since a context of thematic and scale diversity of participants may lead to contradictory conclusions. In this way, and based on the results obtained, it 
appears that the most efficient theatres are those employing a shorter and less diverse scheduling, whilst the best-performing companies (in terms of audience success) are those specialising in dance for children and new formats, and who put on relatively fewer and easier to stage works. These results contradict the aims of the programme, at least those concerned with fostering the production and diversity of dance shows. In fact, this demonstrates that the effectiveness of a single public programme with standard or flat subsidies for artistic creativity is indeed limited, such that we posit the possibility of implementing scaled or discriminatory subsidies in terms of production type or budget thresholds. This would allow certain sectors with less costly performances to be considered separately. For these, it might be appropriate to have lump-sum type funding that would encourage merely bulk production. In contrast, in other sectors, which involve more complex productions, scaled or ad valorem subsidies might be recommendable depending on box-office takings or when justifying budget thresholds. This might help to foster, in a more weighted manner, quality and artistic diversity with audience success. This study does, however, provide a test-bed for evaluating a cultural policy designed to promote dance through the performance of the agents involved therein and opens up fresh lines of research. First, there is the need to consider costs as well as the capital and work resources in each agent in order to conduct allocative efficiency analysis and, second, the possibility of contextual factors that impact how effective the various actors are, and where two-stage efficiency evaluation models might prove to be pertinent. 


\section{Notes}

' See the Danza a Escena (www.danzaaescena.es) programme for further details concerning the requirements and benefits of participating in the programme.

ii No correspondence was established with the objective of stylistic diversity for dance companies since, in practice, entities taking part in the programme only do so with one annual work. The aim of achieving variety in the offer is left to theatres, who can hire at least more than three different shows. As a result, this at least provides an incentive in terms of plurality of styles.

iii In order to standardise data on funding, net amounts have been taken, excluding the effect of taxes. As regards available capacity, this has been calculated as the number of seats at the venue multiplied by the number of performances scheduled.

${ }^{\text {iv }}$ Genres have been differentiated as follows: contemporary dance, neoclassical dance, Spanish dance (flamenco and contemporary Spanish dance), children's dance (for children, the family and all audiences), new formats of dance (urban dance, circus dance, vertical dance, avant-garde proximity shows, physical theatre and techno-dance), and small format shows (solos and short pieces).

${ }^{\checkmark}$ We do not use more sophisticated models such as Network-DEA as in Del Barrio-Tellado et al. (2020) in which the production process is divided into different stages that are more or less controlled by the manager. This is because our purpose is not to measure the efficiency of these agents in the market, but rather to analyse how they optimize their behaviour when fulfilling the goals established in the cultural policy. For this reason, nor do we apply DEA models with a two-stage approach to test the effect of external factors, since our aim is to measure the efficiency of the public programme itself.

vi The selection process is indeed quite selective. For instance, in the last year analysed, 353 proposals were presented, although only 30 dance companies were chosen to form part of the catalogue of shows.

vii This dual behaviour concerning repertoire styles is also found in the programming of Warsaw theatres, as shown in Wisniewska and Czajkowski (2019). 


\section{References}

Aoyam, Y. 2009. "Artist, Tourist, and the State: Cultural Tourism and the Flamenco Industry in Andalusia, Spain." International Journal of Urban and Regional Research 33 (1): 80-104. doi:10.1111/j.1468-2427.2009.00846.x.

Baumol, W. J., and W. G. Bowen. 1966. Performing Arts: The Economic Dilemma. New York: Twentieth Century Fund.

Borowiecki, K., and C. Marvao. 2015. "May I Have this Dance? Dance Participation and Attendance in Denmark." Cultural Trends $26 \quad$ (2): 155-167. doi:10.1080/09548963.2017.1323849.

Castiglione, C., D. Infante, and M. Zieba. 2018. "Technical efficiency in the Italian performing arts companies." Small Business Economics 51 (3): 609-638. doi:10.1007/s11187-017-9931-1.

Charnes A., W. W. Cooper, and E. Rhodes. 1978. "Measuring the Efficiency of Decision Making Units." European Journal of Operational Research 2 (6): 429-444. doi: $\underline{10.1016 / 0377-2217(78) 90138-8 .}$.

Cohen, R., W. Schaffer, and B. Davidson. 2003. 'Arts and Economic Prosperity: The Economic Impact of Nonprofit Arts Organizations and Their Audiences'. Journal of Arts Management Law and Society 33 (1): 17-31. doi: $\underline{\text { 10.1080/10632920309597338 }}$

Del Barrio-Tellado, M. J., L. C. Herrero-Prieto, and C. Murray. 2020. “Audience Success or Art for Art's Sake? Efficiency Evaluation of Dance Companies in the United States." Nonprofit Management and Leadership 31 (1): 129-152. doi:10.1002/nml.21411. 
Fernández-Blanco, V., L. C. Herrero, and J. Prieto-Rodríguez. 2013. "Performance of Cultural Heritage Institutions" in Handbook on the Economics of Cultural Heritage, edited by I. Rizzo, and A. Mignosa, 470-488. Cheltenham: Edward Elgar.

Gómez-Zapata, J., Herrero-Prieto, L. and Rodríguez-Prado, B. (2020). Does music soothe the soul? Evaluating the impact of a music education programme in Medellin, Colombia. Journal of Cultural Economics, doi: 10.1007/s10824-020-09387-z

Heredia-Carroza, J., L. Palma, and A. Marín. 2020. "Determinants of Attendance Frequency to Flamenco Shows in Spain. A Cultural Economic Approach.” Revista de Metodos Cuantitativos para la Economia y la Empresa, 29, 79-98.

Heredia-Carroza, J., L. Palma, and L. F. Aguado. 2019. "Why Does Copyright Ignore Performers? The Case of Flamenco in Spain.” The Journal of Arts Management, Law and Society 49 (5): 347-364. doi:10.1080/10632921.2019.1646682.

Hong, J. 2014. "Data Envelopment Analysis in the Strategic Management of Youth Orchestras." The Journal of Arts Management, Law and Society 44 (3): 181-201. doi: $\underline{10.1080 / 10632921.2014 .937888}$.

Jeffri, J. 2005. “After the ball is over.” International Journal of Cultural Policy 11 (3): 341-355. doi:10.1080/10286630500411499.

Labaronne, L. 2019. “A Resource-Oriented Approach to Performing Arts Organizations: An Ethnographic Study of Dance Companies." The Journal of Arts Management, Law and Society 49 (4): 242-256. doi:10.1080/10632921.2019.1617814.

Lee, D. 2013. 'How the Arts Generate Social Capital to Foster Intergroup Social Cohesion'. Journal of Arts Management Law and Society 43 (1): 4-17. doi: 10.1080/10632921.2012.761167 
Marco Serrano, F. 2006. "Monitoring Managerial Efficiency in the Performing Arts: A Regional Theatres Network Perspective.” Annals of Operations Research 145 (1): 167171. doi:10.1007/s10479-006-0032-9.

Markusen, A. and G. Schrock. 2006. 'The Artistic Dividend: Urban Artistic Specialisation and Economic Development Implications'. Urban Studies 43 (10): 1661-86. doi: $\underline{10.1080 / 00420980600888478}$

Montgomery, S., and M. Robinson. 2003. "What Becomes of Undergraduate Dance Majors? Journal of Cultural Economics 27 (1): 55-71. doi:10.1023/A:1021580130420.

Palma, M., L. Palma, and L. F. Aguado. 2013. "Determinants of Cultural and Popular Celebration Attendance: The Case Study of Seville Spring Fiestas.” Journal of Cultural Economics 37 (1): 87-107. doi:10.1007/s10824-012-9167-5.

Schimmelpfennig, J. 2003. "Ballet" in A Handbook of Cultural Economics, edited by R. Towse, 85-90. Cheltenham: Edward Elgar.

Segers, K., A. Schramme, and R. Devriendt. 2010. "Do Artists Benefit from Arts Policy? The Position of Performing Artists in Flanders (2001-2008)." The Journal of Arts Management, Law and Society 40 (1): 58-75. doi:10.1080/10632921003603919.

Simar, L., and P. Wilson. 1998. "Sensitivity Analysis of Efficiency Scores: How to Bootstrap in Nonparametric Frontier Models." Management Science 44 (1): 49-61. doi: $10.1287 /$ mnsc.44.1.49.

Skinner, J. 2013. "Social Dance for Successful Aging: The Practice of Health, Happiness, and Social Inclusion Amongst Senior Citizens." Anthropology and Aging Quarterly 34 (1): 18-29. doi:10.5195/aa.2013.24. 
Smith, T. 2003. "The Effect of NEA Grants on the Contributions to Nonprofit Dance Companies." The Journal of Arts Management, Law and Society 33 (2): 114-126. doi: $10.1080 / 10632920309596569$.

Wu, J., J. Keshen, and C. Yuan. 2020. "Market-Oriented Reforms, Economic Efficiency and Commercial Performing Arts y China." The Journal of Arts Management, Law and Society 50 (1): 33-51. doi:10.1080/10632921.2019.1664692.

Zieba, M. 2011. “An Analysis of Technical Efficiency and Efficiency Factors for Austrian and Swiss Non-Profit Theatres." Swiss Journal of Economics and Statistics 147 (2): 233274. doi:10.1007/BF03399346. 


\section{TABLES}

Table 1. The dance support programme: main features (2011-2016)

\begin{tabular}{|c|c|}
\hline Stakeholders & $\begin{array}{c}\text { Venues: } 161 \\
\text { Dance companies:91 }\end{array}$ \\
\hline Venue capacity & $\begin{array}{l}\text { mean: } 537 \\
\text { max: } 3,000 \\
\min : 65\end{array}$ \\
\hline Cultural productions & $\begin{array}{c}\text { funded works: } 122 \\
\text { funded shows: } 658 \\
\text { non-funded shows: } 88\left({ }^{*}\right)\end{array}$ \\
\hline Spectators & $\begin{array}{c}\text { total: } 126,642 \\
\text { per company: } 1,392 \\
\text { per venue: } 787 \\
\text { per show: } 192\end{array}$ \\
\hline Funding & $\begin{array}{c}\text { total: } 1,547,936 € \\
\text { per spectator: } 12 € \\
\text { per show: } 2,352 € \\
\text { per work: } 12,688 € \\
\text { per venue: } 9,614 €\end{array}$ \\
\hline
\end{tabular}

(*) Shows performed outside of the subsidy, financed by the venues' own funds Source: Annual Danza a Escena reports and authors' own.

Table 2. Variables and descriptive statistics

\begin{tabular}{|c|c|c|c|c|c|c|c|}
\hline Variables & & Mean & Median & Min. & Max. & Range & St Dev. \\
\hline FUNDING PV & $\begin{array}{l}\text { Funding provided by the programme } \\
\text { to each venue. }\end{array}$ & $12,615.89$ & $7,577.25$ & $1,875.00$ & $60,898.64$ & $59,023.64$ & $12,682.46$ \\
\hline \multirow[t]{2}{*}{ CAPACITY PV } & No. of tickets made available by the & & & & & & \\
\hline & $\begin{array}{l}\text { venues (capacity multiplied by } \\
\text { performances and shows). }\end{array}$ & $3,431.63$ & $2,274.00$ & 130.00 & $29,844.00$ & $29,714.00$ & $4,232.78$ \\
\hline SPECTATORS PV & $\begin{array}{l}\text { No. of spectators attending the dance } \\
\text { shows programmed for venues. }\end{array}$ & 938.76 & 612.00 & 69.00 & $3,779.00$ & $3,710.00$ & 868.24 \\
\hline WORKS PV & $\begin{array}{l}\text { No. of different works programmed for } \\
\text { each venue. }\end{array}$ & 5.45 & 3.00 & 2.00 & 24.00 & 22.00 & 5.06 \\
\hline GENRES & $\begin{array}{l}\text { No. of different genres into which the } \\
\text { works programmed can be classified }\end{array}$ & 3.32 & 3.00 & 1.00 & 10.00 & 9.00 & 2.07 \\
\hline FUNDING DC & $\begin{array}{l}\text { Funding received by each dance } \\
\text { company taking part in the programme }\end{array}$ & $15,509.48$ & $10,500.00$ & $1,000.00$ & $94,350.00$ & $93,350.00$ & $15,423.43$ \\
\hline WORKS DC & $\begin{array}{l}\text { No. of works with which the company } \\
\text { takes part in the programme }\end{array}$ & 1.34 & 1.00 & 1.00 & 3.00 & 2.00 & 0.56 \\
\hline SPECTATORS DC & $\begin{array}{l}\text { No. of spectators who have watched } \\
\text { the shows staged by each company }\end{array}$ & $1,293.85$ & 678.00 & 11.00 & $10,737.00$ & $10,726.00$ & $1,764.89$ \\
\hline
\end{tabular}

Source: Danza a escena programme and authors' own 
Table 3. Mean efficiency levels of venues and dance companies

\begin{tabular}{lcccccc}
\hline & TE & PTE & SE & Bootstrap & Bootstrap & Bootstrap \\
& & & & TE & PTE & SE \\
\hline Performance venues & & & & & & \\
$\quad$ Multi-output model & 60.07 & 84.49 & 71.39 & 54.91 & 82.04 & 67.19 \\
$\quad$ Demand oriented model & 42.59 & 53.22 & 84.06 & 38.07 & 49.19 & 77.38 \\
$\quad \begin{array}{l}\text { Supply oriented model } \\
\text { Dance companies }\end{array}$ & 47.46 & 76.31 & 63.01 & 42.55 & 72.95 & 58.33 \\
$\quad$ Audience success model & 35.86 & 42.21 & 86.88 & 31.90 & 38.08 & 83.77 \\
Source: authors' own & & & & & &
\end{tabular}

Source: authors' own

Table 4. Venue efficiency ranges: multi-output model

\begin{tabular}{c|crrrrrr}
\hline $\begin{array}{c}\text { Efficiency } \\
\text { range }\end{array}$ & $\begin{array}{c}\text { No. of } \\
\text { venues }\end{array}$ & $\begin{array}{c}\text { Mean } \\
\text { efficiency }\end{array}$ & $\begin{array}{c}\text { Mean no. of } \\
\text { spectators }\end{array}$ & $\begin{array}{c}\text { Mean no. of } \\
\text { works }\end{array}$ & $\begin{array}{c}\text { Mean no. of } \\
\text { genres }\end{array}$ & $\begin{array}{c}\text { Mean no. of } \\
\text { tickets offered }\end{array}$ & Mean capacity \\
\hline $0-20$ & 0 & - & - & - & - & - & - \\
$20-40$ & 7 & 35.83 & $1,317.57$ & 8.86 & 4.71 & $10,130.00$ & $1,028.43$ \\
$40-60$ & 47 & 48.80 & 946.21 & 5.77 & 3.72 & $3,891.60$ & 638.06 \\
$60-80$ & 31 & 67.79 & 949.61 & 5.42 & 3.00 & $2,101.45$ & 450.35 \\
$80-100$ & 13 & 95.46 & 681.92 & 2.54 & 1.85 & $1,333.85$ & 433.77 \\
\hline
\end{tabular}

Table 5. Venue efficiency ranges: demand model

\begin{tabular}{c|ccrrrrr}
\hline $\begin{array}{c}\text { Efficiency } \\
\text { range }\end{array}$ & $\begin{array}{c}\text { No. of } \\
\text { venues }\end{array}$ & $\begin{array}{c}\text { Mean } \\
\text { efficiency }\end{array}$ & $\begin{array}{c}\text { Mean no. of } \\
\text { spectators }\end{array}$ & \multicolumn{1}{c}{$\begin{array}{c}\text { Mean no. of } \\
\text { works }\end{array}$} & $\begin{array}{c}\text { Mean no. of } \\
\text { genres }\end{array}$ & $\begin{array}{c}\text { Mean no. of } \\
\text { tickets offered }\end{array}$ & $\begin{array}{c}\text { Mean } \\
\text { capacity }\end{array}$ \\
\hline $0-20$ & 16 & 14.85 & 636.00 & 6.00 & 3.75 & $5,961.81$ & 824.88 \\
$20-40$ & 34 & 32.12 & 966.97 & 5.88 & 3.62 & $3,881.82$ & 582.09 \\
$40-60$ & 29 & 50.22 & $1,140.48$ & 6.66 & 3.72 & $2,755.86$ & 437.72 \\
$60-80$ & 14 & 66.68 & 726.79 & 2.43 & 1.86 & $1,349.93$ & 579.21 \\
$80-100$ & 5 & 90.81 & $1,139.20$ & 2.20 & 1.60 & $2,022.00$ & 599.20 \\
\hline
\end{tabular}


Table 6. Venues efficiency ranges: supply model

\begin{tabular}{c|ccrrrrr}
\hline $\begin{array}{c}\text { Efficiency } \\
\text { range }\end{array}$ & $\begin{array}{c}\text { No. of } \\
\text { venues }\end{array}$ & $\begin{array}{c}\text { Mean } \\
\text { efficiency }\end{array}$ & $\begin{array}{c}\text { Mean no. of } \\
\text { spectators }\end{array}$ & $\begin{array}{c}\text { Mean no. of } \\
\text { works }\end{array}$ & $\begin{array}{c}\text { Mean no. of } \\
\text { genres }\end{array}$ & $\begin{array}{c}\text { Mean no. of } \\
\text { tickets offered }\end{array}$ & Mean capacity \\
\hline $0-20$ & 0 & - & - & - & - & - & - \\
$20-40$ & 37 & 34.52 & $1,299.54$ & 5.68 & 3.49 & $4,879.14$ & 718.81 \\
$40-60$ & 44 & 46.71 & 864.98 & 6.11 & 3.64 & $3,178.82$ & 565.59 \\
$60-80$ & 12 & 69.89 & 372.92 & 3.42 & 2.17 & $1,052.00$ & 351.50 \\
$80-100$ & 5 & 96.01 & 276.20 & 2.80 & 2.00 & 656.00 & 217.60 \\
\hline
\end{tabular}

Table 7. Dance companies efficiency ranges: Audience success model

\begin{tabular}{c|crrrr}
\hline Efficiency range & $\begin{array}{c}\text { No. of } \\
\text { companies }\end{array}$ & Mean efficiency & $\begin{array}{c}\text { Mean no. of } \\
\text { works }\end{array}$ & No. of shows & $\begin{array}{c}\text { Mean no. of } \\
\text { spectators }\end{array}$ \\
\hline $0-20$ & 25 & 12.91 & 1.20 & 3.80 & 323.88 \\
$20-40$ & 39 & 28.21 & 1.38 & 6.03 & 870.79 \\
$40-60$ & 10 & 46.51 & 1.40 & 8.20 & $1,614.60$ \\
$60-80$ & 8 & 67.68 & 1.25 & 8.50 & $2,132.25$ \\
$80-100$ & 9 & 92.64 & 1.56 & 19.78 & $4,719.78$ \\
\hline
\end{tabular}

Table 8. Efficiency indices and level of participation in the programme by dance company style

\begin{tabular}{lrrrrrrrr}
\hline No. of companies & \multicolumn{1}{c}{$\begin{array}{c}\text { No. of } \\
\text { companies }\end{array}$} & $\begin{array}{c}\text { Mean Tech. } \\
\text { Eff. }\end{array}$ & $\begin{array}{c}\text { Pure Tech. } \\
\text { Eff }\end{array}$ & $\begin{array}{c}\text { Mean } \\
\text { Scale } \\
\text { Efficiency }\end{array}$ & Funding & Works & Shows & Audience \\
\hline Contemporary dance & 32 & 22.80 & 28.14 & 86.82 & 444,575 & 46 & 173 & 23,013 \\
Neoclassical dance & 6 & 34.80 & 46.79 & 76.17 & 129,014 & 9 & 39 & 8,178 \\
New formats & 14 & 52.22 & 57.62 & 89.41 & 289,492 & 19 & 138 & 31,542 \\
Spanish dance & 9 & 27.32 & 37.85 & 80.95 & 146,360 & 12 & 52 & 8,574 \\
Children & 23 & 50.04 & 55.75 & 91.94 & 376,207 & 29 & 235 & 44,280 \\
Small format & 7 & 28.09 & 32.86 & 82.25 & 25,714 & 7 & 21 & 2,153 \\
\hline
\end{tabular}




\section{FIGURES:}

Figure 1. The dance support programme: territorial distribution of stakeholders and main results.

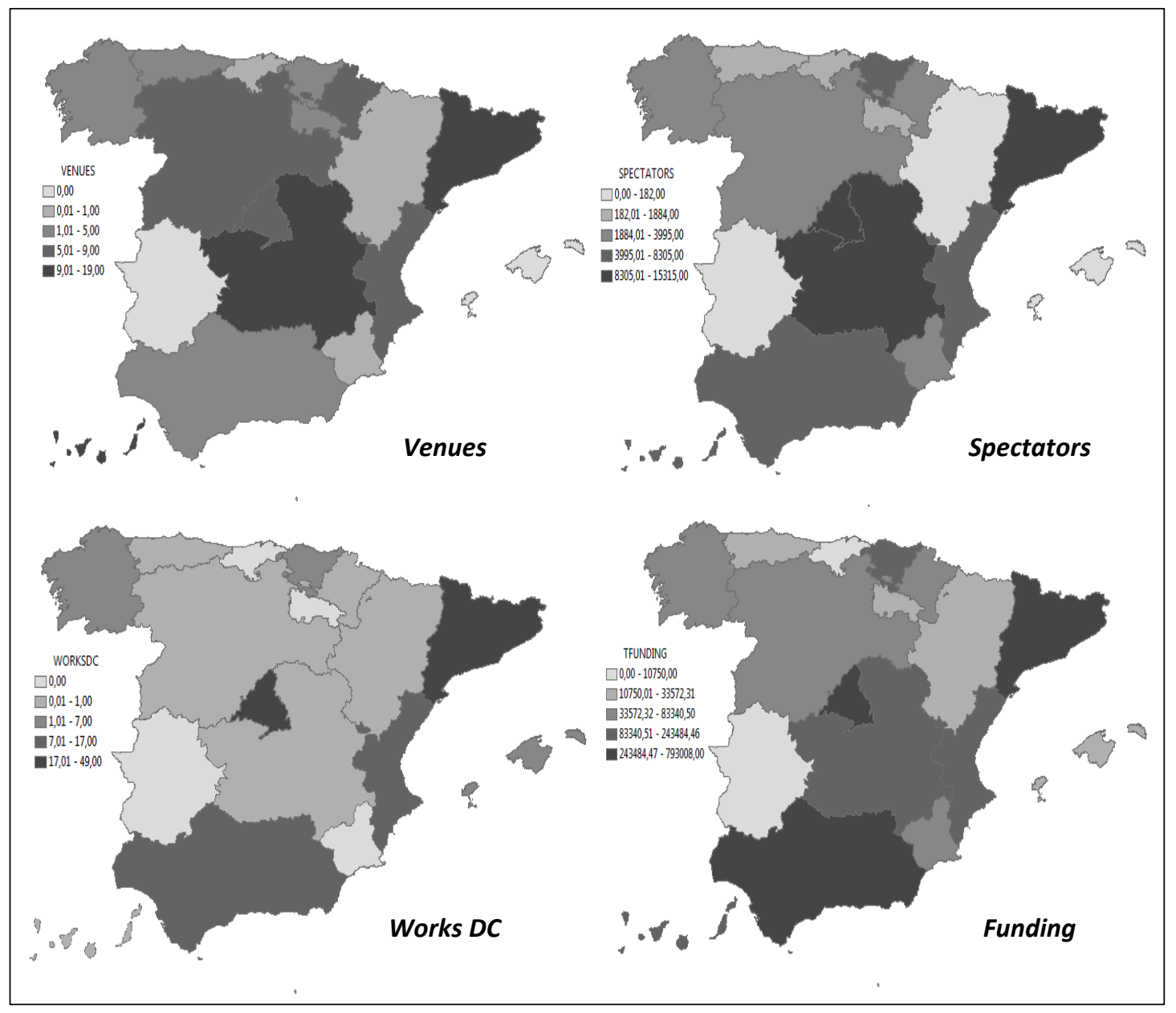

Figure 2. DEA models for evaluating stakeholder performance in the public cultural programme.

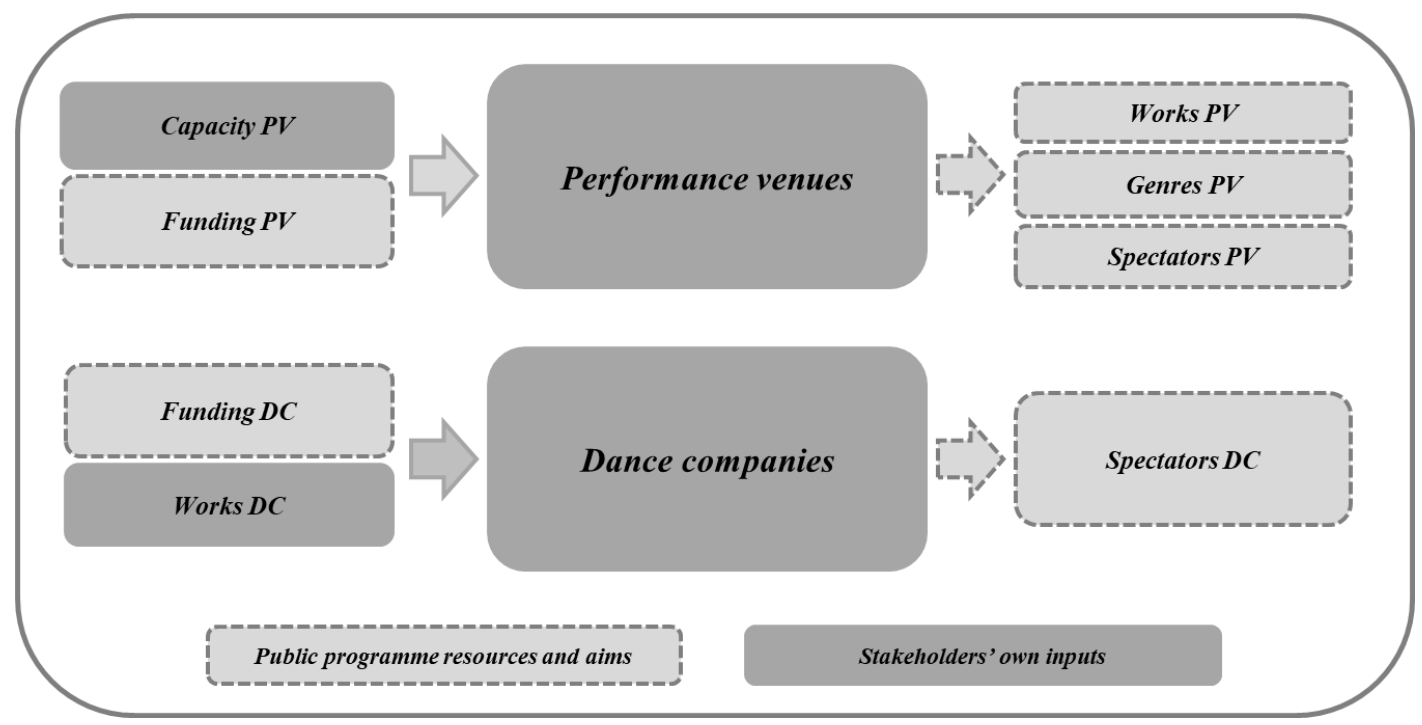

